\title{
Study on the Development of Green Logistics of Agricultural Products under the New Economic Status
}

\author{
Aidong Wu \\ Xijing University, Xi'an, 710123
}

\section{Keywords: Green Logistics, Agricultural Products, New Economic Norm}

\begin{abstract}
At present, Chinese economic development into the new normal, how to slow down the background of economic growth continue to strengthen the basic position of agriculture and promote farmers to continue to increase income, is a major issue must be cracked. Agricultural logistics is a branch of the logistics industry, but also an important part of agricultural production and management activities, for the sustainable development of agricultural economy and farmers have an important role. Agricultural logistics is the main target of agricultural and sideline products, through the processing of storage packaging and distribution and other links to promote the preservation and appreciation of agricultural products, and ultimately distributed to consumers in the hands of economic activities. The main purpose of agricultural logistics is to save the cost of circulation, reduce the flow loss, improve the efficiency of circulation and increase the added value of agricultural products. The development direction includes not only one-way logistics from rural to urban areas, but also agricultural production materials or industrial consumption from urban to rural areas Logistics.
\end{abstract}

\section{Introduction}

Chinese agricultural logistics industry started late, green agricultural logistics has just risen, people's understanding of it is still very limited, in the agricultural green logistics service level and research is still in its infancy.

Chinese agricultural products, logistics losses have much higher than the developed countries and even some developing countries, the loss rate. Many aspects of the flow of agricultural products are in the high cost of the higher cost of circulation. With the specialized production, the circulation of agricultural products will be more and more, if there are no corresponding measures to reduce logistics costs, the cost will show a growing trend. In addition, the loss of agricultural production is also great, nearly three years, the national pest and rodents annual incidence of 54 million mu, although the control to restore a lot of economic losses, but still lose 40 million tons of grain per year, Production of $8.8 \%$, other crops such as cotton loss rate of $24 \%$, vegetable and fruit loss rate of $20 \%$ to $30 \%$.

On the one hand, the concept of leadership and government has not changed, the idea of green logistics of agricultural products has not yet established, the lack of development of forward-looking, and the pace of the gap there is a gap. On the other hand, producers and consumers of foreign agricultural products logistics green business consumption concept is still very weak, green logistics ideas almost zero. Producers show us green products, green signs, green marketing and green services, consumers are looking for green consumption, green enjoyment and green security, and one of the green channel --- logistics links, no one is enough Attention and concern. Therefore, in the development of agricultural logistics at the same time, as soon as possible 
to raise awareness and update ideas, green agricultural products as the world's all-round green revolution an important part of recognition and green logistics for the future.

\section{The Importance of Establishing Green Logistics System for Agricultural Products}

Into the 21st century, the development of the logistics industry will be the effective use of resources and environmental protection of the green logistics as the first development, the world is also trying to promote the integration of agricultural green logistics as the focus of the development of the logistics industry. We will strengthen the establishment and improvement of the policy and theoretical system of greening of agricultural products logistics, improve and adjust the objectives of agricultural products logistics system, logistics facilities and logistics activities, update the concept, set up the green logistics integration system of agricultural products, realize the agricultural product logistics The overall system optimization and the minimum damage to the environment will be conducive to the improvement of Chinese agricultural logistics management level for Chinese economic development is of great significance.

Chinese agricultural green logistics and developed countries there is a big gap between the green agricultural products for us, there is a long way for a long way. 2008 Beijing Olympic Games has also become the focus of the industry, almost all large logistics enterprises are studying the 2008 "Green Olympics" brought about by the Olympic logistics business opportunities, while Chinese accession to the WTO after the infiltration of foreign logistics enterprises, is bound to domestic logistics Industry, especially the development of agricultural products to bring the impact of this time, Chinese construction of modern green logistics integration system to promote energy efficient, green, not only necessary, but also urgent, but also to deal with future challenges and in the competition Win a good opportunity.

To establish agricultural products green channel, a lot of ways, the road is very broad. Modern logistics is to logistics and distribution of large-scale, fast, wide radiation and high efficiency known. It is an important link to promote the industrialization of agriculture. The key to realizing the final value is the effective measure to improve the agricultural efficiency and increase the income of the peasants. Therefore, we use the concept of modern logistics, vigorously expand into rural areas, for farmers to serve the field, so that agricultural products in the flow of the maximum value-added.

\section{Agricultural Green Logistics Development Direction}

Lean Logistics As a new concept of modern management, the core of its thinking is to create as much as possible with fewer and fewer inputs - less manpower, less equipment, shorter times and smaller venues; Also more and more close to the user, to provide customers really want something. Lean Logistics believes that all non-value-added activities are likely to cause waste, including waste of excess production, waiting for waste, waste of transportation, waste of improper process operations, and waste of excess inventory. Therefore, the lean logistics of agricultural products through the development and design of lean processes to minimize waste, the implementation of the consumer's lean and personalized services to achieve the optimal allocation of resources in the agricultural supply chain.

Agile logistics is in the face of changing demand and diversification of customer needs in the case of elimination of waste is not as good as the changing market conditions for rapid response is more important, while the time sensitive, difficult to store agricultural products, if the vegetables Products, consumers are mostly willing to buy fresh products, product prices are also due to fresh 
and different, as well as market opportunities, corruption easily rotten, poor sales and other issues. Agile logistics is mainly through the logistics, information flow, capital flow control, suppliers, manufacturers, distributors, retailers and consumers integrated into a unified, fast response, the higher the degree of seamless function Logistics network chain. Therefore, the agricultural lean logistics to meet the needs of the fastest response speed is conducive to improving logistics efficiency and efficiency.

Agricultural products because of its own special biological properties, so that agricultural logistics process with high energy consumption, high emission characteristics. Low-carbon logistics of agricultural products is a model that uses energy efficiency technology, renewable energy technology and greenhouse gas emission reduction technologies to reduce carbon emissions in agricultural logistics activities and improve the efficiency of logistics resources with low energy consumption, low pollution and low emission. The development of low-carbon logistics should be based on coordination with the environmental carrying capacity, based on the sustainable development of agricultural economy and resources and environment, agricultural logistics is the future development trend. Therefore, in the era of low-carbon economy, low-carbon logistics of agricultural products is an inevitable choice for the sustainable development of the logistics industry, to achieve low carbonation of agricultural logistics is low-carbon economy and low-carbon logistics development of the important foundation and protection.

Recycling of agricultural products is the circulation of agricultural products from the supply to the demand at the same time, the packaging, processing scrap, garbage and other waste collection for processing, processing or multi-level use, to re-use the value of the logistics process. Such as agricultural products produced by the by-products and agricultural products after the surplus can be converted into feed, feed for feeding livestock products, and then into the agricultural products circulation system. According to the data show that only the vegetables in the vegetables and vegetables in the results of the comparison, 100t hairy vegetables can produce 100t garbage, which can be seen from the wool produced by the waste or directly into the sales of the huge and inefficient logistics costs are agricultural products The problem of circulating logistics.

\section{Promote the Green Development of Chinese Agricultural Products Logistics Mechanism}

Green logistics is the future trend and inevitable requirement of agricultural product logistics and its sustainable development. On the management and control of agricultural green logistics management, can be divided into social decision-making level, enterprise management and job management and other three levels of green logistics activities, and vigorously promote the development of green logistics must be through government, enterprises, farmers and other aspects Work together. Among them, the social decision-making (mainly government) is the main function of the policy, laws and regulations through the dissemination of green ideas, construction of agricultural products conducive to the development of green logistics system.

Government and relevant departments to develop relevant policies, focusing on supporting the main producing areas of large agricultural products, modern warehousing and logistics facilities, improve the fresh agricultural products cold chain logistics system. For the use of green technology and equipment companies can give green subsidies, differential rates, credit support and so on. Support and cultivate new, green and large-scale agricultural logistics main body, to guide a group of strong, reputable, well-established agriculture and related industries of large and medium-sized enterprises engaged in agricultural logistics. It speeds up the development of agricultural products logistics standards, the implementation of strict green logistics technical regulations; the establishment of agricultural products logistics information management system to trace the quality 
of food safety and circulation of green. Through policy support, and guide the main body of agricultural logistics to change the external diseconomy of circulation, and thus meet the requirements of green economic development.

The country formulated and promulgated a number of environmental protection, pollution control policies and regulations, but for the logistics industry is not much. The lack of relevant legal system will lead to the development of green logistics without rules, can not follow. To speed up the establishment of agricultural products logistics standardization system, agricultural logistics tracking system, inspection and quarantine and quality supervision system and market access system. We should strengthen the system of promoting fair trade of agricultural products and improve the efficiency of circulation, further improve the mechanism of incentive and restraint on green logistics of agricultural products, formulate supervision and regulation of laws and regulations, and restrict the circulation behavior of logistics enterprises.

Favorable fiscal policy, tax policy, monetary policy and interest rate policy are the powerful means of developing green logistics of agricultural products. To set up the corresponding financial and financial measures to provide low-interest loans for farmers and farmers' marketing organizations to provide corresponding tax incentives for agricultural green logistics enterprises; to actively guide the establishment of diversified investment financing mechanism to support agricultural logistics enterprises through the mutual insurance\% UNPROFOR and other forms of credit guarantee system, financial institutions through the construction of information evaluation system and green project evaluation mechanism to build credit system, to build a financing platform.

\section{Conclusion}

At present, most of our farmers still have to find their own sales of agricultural products, self-logistics easily lead to low efficiency. To actively encourage and develop agricultural marketing organizations to support third-party logistics enterprises bigger and stronger, to improve the degree of organization, to overcome the family as a unit of decentralized production, decentralized management practices and the low efficiency of agricultural products logistics problems. Government and relevant departments should give some input or support, guide and support the establishment of information and cooperation mechanism between production and market, agricultural product logistics enterprise information system and customer information system compatibility and sharing, according to market information to arrange production and Storage and transportation.

\section{References}

[1] Wu Xiaoyan. Study on optimization strategy of agricultural product logistics financial model [J]. China Business, 2012 (25)

[2] Shen Lili. Agricultural logistics and financial development issues and strategies [J]. Rural economy, 2012 (07)

[3] Luo Yuelong, Chen Taiguang. Study on the "Financial Warehouse" Model Based on Innovation of Logistics Financial Service [J]. Economic Issues, 2012 (01)

[4] Yuan Yuchun. Study on Chinese agricultural product logistics financial service model [J]. Anhui Agricultural Sciences, 2011 (30)

[5] Wang Dupeng, Wang Hong, Zhou Jing. Evaluation of logistics financial service value from the perspective of symbiosis theory [J]. Softian Science, 2010 (10) 
[6] Yang Weixia. Agricultural product supply chain logistics financial model [J]. Commercial times, $2010(15)$ 